\title{
Internodal length of sural nerve fibres in chronic occlusive vascular disease
}

\author{
J. S. CHOPRA ${ }^{1}$ AND L. J. HURWITZ \\ From the Department of Medicine, Queen's University of Belfast, and the Department of Neurology, \\ Royal Victoria Hospital, Belfast
}

Changes with age in internodal length in the sural nerve in man have been discussed by Lascelles and Thomas (1966). They reported their findings in the sural nerve obtained at necropsy in 14 subjects of ages ranging from 18 to 80 years. In the 10 subjects under the age of 65 years the correlation between internodal length and the maximum diameter of single nerve fibres was found to be close, especially in the younger subjects. In the other four subjects (aged 68, 73, 74, and 80 years) there were abnormally short internodal lengths, which on analysis were considered to result mainly from segmental demyelination and remyelination and also regeneration after complete degeneration of the fibres. Lascelles and Thomas considered ischaemia secondary to occlusive disease of the vasa nervorum as a possible explanation of these degenerative changes occurring in peripheral nerve fibres in later life. In the present study the sural nerve has been examined in six patients with severe occlusive vascular disease in the legs, of whom three were in the relatively young, under-50, age group. The series provided an opportunity of considering the effects of ischaemia as the main or only pathological factor damaging the nerve.

\section{MATERIAL AND METHODS}

The sural nerve was obtained by biopsy in five patients. Prior permission was given by the patients, and the procedure and the information that could be expected explained to them. In all, the biopsy incision healed normally and after some weeks there was little objective change in sensation in the sural nerve distribution. In the other patient the sural nerve was taken in the operating theatre from the amputated limb. In two patients the biopsy was taken under local anaesthesia and in the other four under general anaesthesia at the time of the definitive operation. In each case the nerve was taken at the level of the lateral malleolus where it was identified posterior to the short saphenous vein. One of us was present when the nerve was taken to ensure its removal from a constant site.

'Supported by the Medical Research Council.
The clinical features are summarized in Table I. The aortogram from case 2 is shown in Figure 1. All the patients had intermittent claudication as a major complaint with progressing disability from this symptom. An oral glucose tolerance test in each patient was normal. Case 2 complained of impotence for three months. Case 3 was noted to have xanthelasma and hypercholesterolaemia but no xanthomatous infiltration was

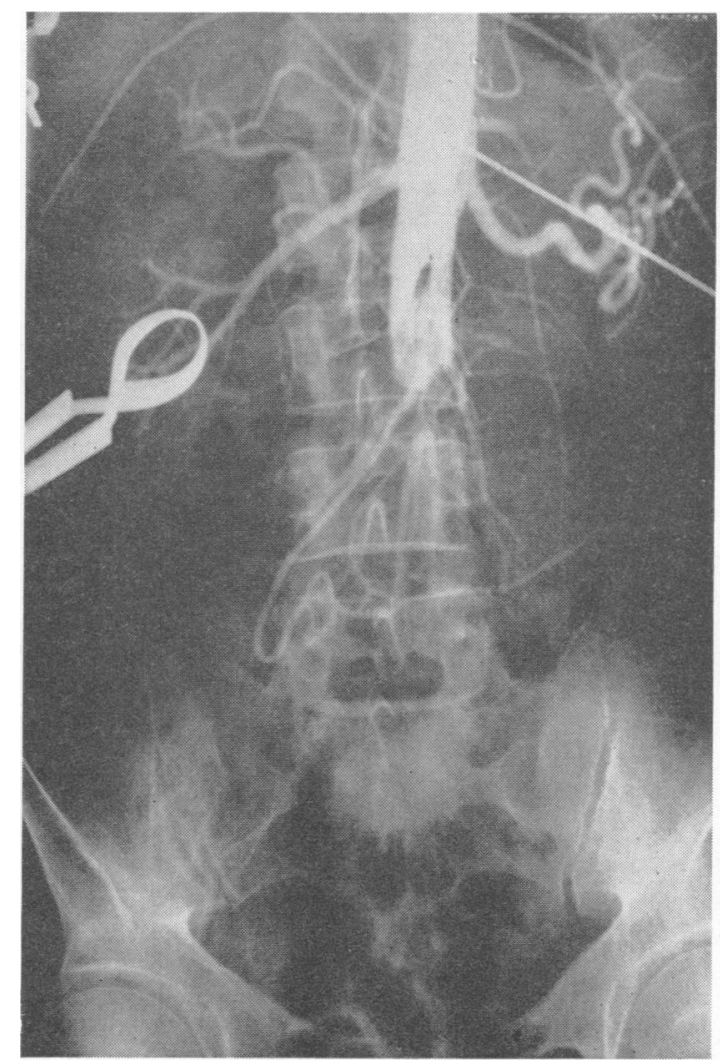

FIG. 1. Aortogram of case 2 showing block of aorta above the superior mesenteric artery. 
TABLE I

CLINICAL SUMMARY OF THE SIX MALE CASES

\begin{tabular}{llll}
$\begin{array}{l}\text { Case Age } \\
\text { No. }\end{array}$ & $\begin{array}{l}\text { Duration and } \\
\text { Degree of } \\
\text { Intermittent } \\
\text { Claudication }\end{array}$ & $\begin{array}{l}\text { Peripheral Puraesthesia Abnormal } \\
\text { Pulses Absent }\end{array}$ & $\begin{array}{l}\text { Abnotogical Signs } \\
\text { Neurology }\end{array}$ \\
\hline
\end{tabular}

$\begin{array}{ll}\text { Angiography } & \begin{array}{l}\text { Sural } \\ \text { Nerve } \\ \text { Biopsy }\end{array}\end{array} \quad$ Treatment

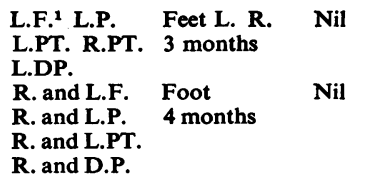

$\begin{array}{lll} & \text { Feet } & \text { Nil }\end{array}$

3

\begin{tabular}{|c|c|c|c|}
\hline 45 & $\begin{array}{l}3 \text { years, right leg, } \\
2 \frac{1}{d} \text { years, left leg, } \\
100 \text { yards }\end{array}$ & $\begin{array}{l}\text { R.F. L.F. }{ }^{1} \\
\text { R. and L.P. } \\
\text { R. and L.PT. }\end{array}$ & $\begin{array}{l}\text { Feet } \\
1 \frac{1}{2} \text { years }\end{array}$ \\
\hline 57 & $\begin{array}{l}1 \text { year, right leg, } \\
150 \text { yards }\end{array}$ & $\begin{array}{l}\text { R.F. R.P. } \\
\text { R.PT. }\end{array}$ & $\begin{array}{l}\text { R. foot } \\
6 \text { months }\end{array}$ \\
\hline 64 & $\begin{array}{l}9 \text { years, left leg, } \\
50 \text { yards }\end{array}$ & $\begin{array}{l}\text { L.F. } \\
\text { R. and L.P. } \\
\text { R. and L.PT. } \\
\text { R. and L.DP. }\end{array}$ & $\begin{array}{l}\text { L. foot } \\
2 \text { years }\end{array}$ \\
\hline
\end{tabular}

R. and L.F. ${ }^{1}$ Both feet R. and L.P. 2 years R. and L.PT. R. and L.DP.

Reduced vibration
$R$. and L. ankles
Slight weakness left
leg and foot. Dim-
inished cotton wool
and pinprick sensit-
ivity over L. foot up
to ankle. Reduced
vibration left ankle
Absent cotton wool
toes of left foot.
Diminished pin-
prick over whole of
left foot. Absent
vibration left ankle
and reduced over
right ankle
F. = Femoral
P. $=$ Popliteal
Atherosclerosis

Atherosclerosis, embolism from rheumatic heart disease

R. = Right L. $=$ Left

${ }^{1}$ Pulse not absent but grossly diminished.

seen in the sural nerve when this was examined histologically. Case 5 had pain in the legs at rest and he had an obstinate ulcer $3 \times 2$ inches (present for five years) over the left tibia.

Sural nerve samples were also taken at necropsy from two subjects (males aged 44 and 54 years) who died following an accident, but were known from the clinical case records of their previous admission to hospital to be non-diabetic with good arterial peripheral pulsations. Histological sections of the peripheral vessels showed no abnormal changes. These sural nerves served as controls.

TECHNIQUE OF PREPARATION OF THE SURAL NERVE A length of about $3 \mathrm{~cm}$. of the sural nerve was taken at biopsy, and divided into three parts. One part was placed on a cardboard at its original length and fixed in $10 \%$ formol saline for 24 hours. Affer further washing, the nerve was immersed in a mixture of glycerine and water in the proportion of 2 to 1 for 48 hours. The latter procedure facilitated the process of the teasing of the single nerve fibres, which was carried out under the dissecting microscope in pure glycerine, with the help of fine mounted needles. After isolation, each fibre was transferred to a slide on which drops of creosote had been placed. About 20 fibres of varying diameter were isolated in this way. The creosote was drained off, the fibres blotted and straightened again under the dissecting microscope and mounted in Canada balsam of low viscosity to avoid displacement of the fibres. The slides were then dried in an oven at $37^{\circ} \mathrm{C}$.

Measurements were made by means of a microscope using an eyepiece micrometer carrying a scale of $1 \mathrm{~cm}$. in length with 100 subdivisions. The internodal lengths were measured at a magnification of $\times 100$. Readings of the diameter were taken under an oil immersion objective at a magnification of $\times 1,000$. For the diameter, a mean of five readings was taken, the reading being taken at an approximately equal distance apart along each internode.

From the other two parts of the nerve specimen taken each sural nerve was also studied in transverse section after staining with haematoxylin and eosin, Glee's Marsland silver impregnation technique and Kultschistsky's haematoxylin stain for myelin sheaths.

\section{RESULTS}

For each nerve the lengths of individual internodes were plotted graphically against the mean diameter readings. Internodal lengths have also been plotted against the diameter of the widest internode on each fibre isolated. This latter technique of plotting the results suggested by Fullerton, Gilliatt, Lascelles, and Morgan-Hughes (1965) allows a convenient 


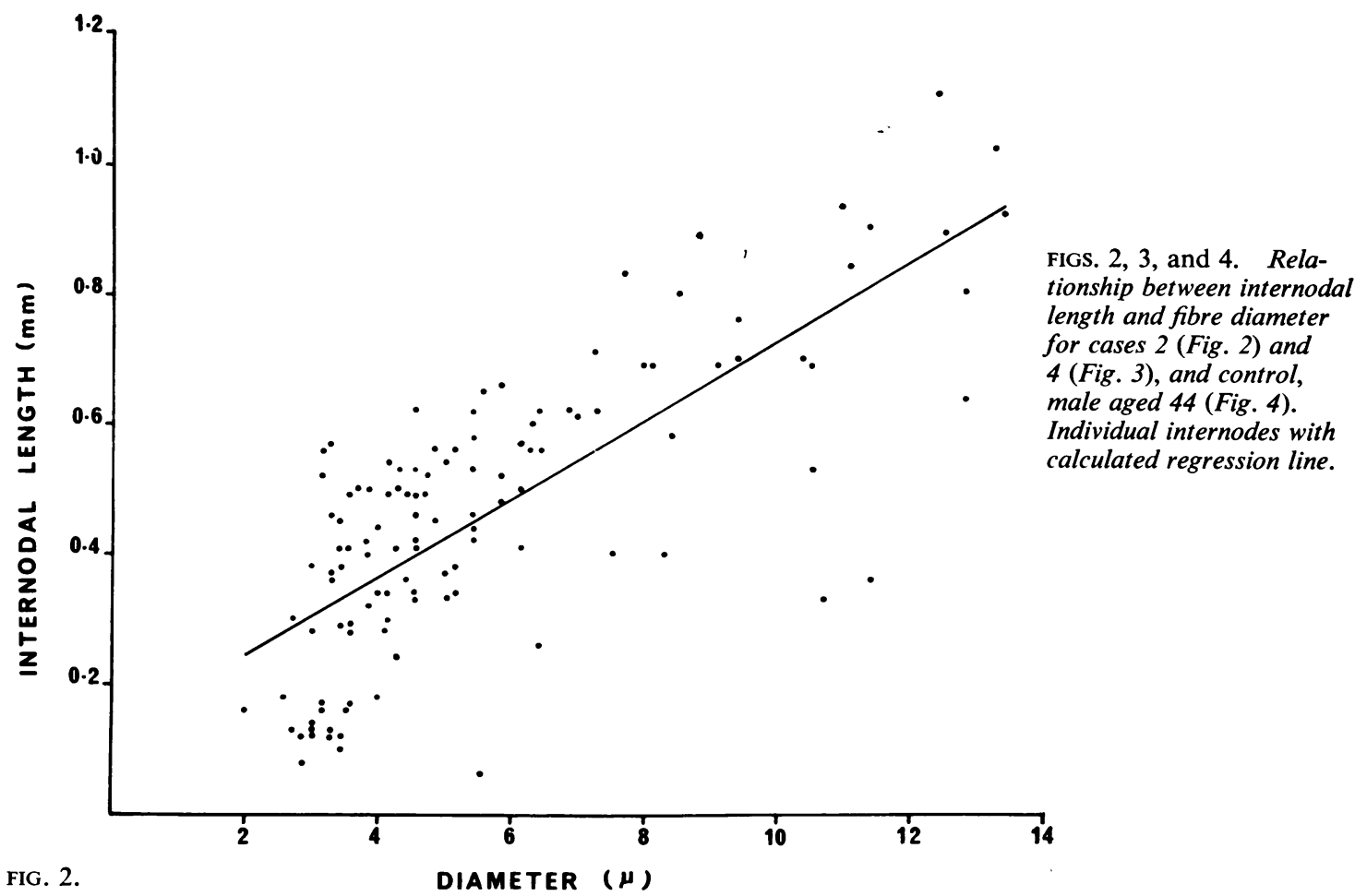

visual assessment of the pattern of variation in internodal distances. The internodal length varied from $0.06 \mathrm{~mm}$. to $1.35 \mathrm{~mm}$. The correlation between internodal length and fibre diameter for cases 2 and 4 is illustrated in Figures 2 and 3. The regression lines for each graph have been calculated. For the patients the slopes are less than the slopes of the regression lines for the two controls (Fig. 4). The reduced slope of the regression line indicates the presence of internodes of shorter length than normal. There is also a wider scatter in the observations than in the control nerves. The correlation and regression coefficients, and residual variances about the regression lines for all the nerves (six patients and two controls), using the same statistical analysis as Lascelles and Thomas (1966), are shown in Table II. The variances in general indicate a wider scatter in all the patients than in the two controls.

The distribution of internodal lengths on single nerve fibres in cases 2 and 4 is shown in Figs. 5 and 6, and for the control in Figure 7. It is apparent that some abnormally short internodes are on fibres that also possess internodes of normal length. This variation in internodal distance suggests segmental demyelination and remyelination rather than regen-

\begin{tabular}{cccrrr}
\multicolumn{7}{c}{ TABLE II } \\
Case No. $\begin{array}{c}\text { No. of } \\
\text { Internodes } \\
\text { Examined }\end{array}$ & $\begin{array}{l}\text { Correlation } \\
\text { Coefficient }\end{array}$ & $\begin{array}{l}\text { Y-axis } \\
\text { Intercepts }\end{array}$ & $\begin{array}{l}\text { Regression } \\
\text { Coefficient }\end{array}$ & $\sigma^{2} \mathrm{r}^{1}$ \\
\hline 1 & 118 & 0.887 & -0.0390 & 0.0752 & 0.02021 \\
2 & 126 & 0.756 & 0.1294 & 0.0595 & 0.02079 \\
3 & 162 & 0.844 & 0.0266 & 0.0648 & 0.01462 \\
4 & 157 & 0.673 & 0.1105 & 0.0438 & 0.02436 \\
5 & 138 & 0.759 & -0.0443 & 0.0584 & 0.01776 \\
6 & 121 & 0.761 & 0.1143 & 0.0491 & 0.01436 \\
Controls & 110 & 0.919 & -0.0911 & 0.0776 & 0.01175 \\
1 & 111 & 0.944 & 0.0898 & 0.0498 & 0.00317
\end{tabular}

${ }^{1}$ Residual variance about regression lines.

eration after Wallerian degeneration (Fullerton et al., 1965; Thomas and Lascelles, 1965). Cases 1-6 showed this segmental demyelination (Fig. 8) but least of all in case 1 , and in cases 5 and 6 there is, in addition to segmental demyelination, some evidence of fibre degeneration and regeneration.

The sural nerve on transverse section showed no perineural thickening and by naked eye there was no obvious loss of myelinated fibres. A more detailed account of the histology of the sural nerve in these and in diabetic patients is to be published later. 

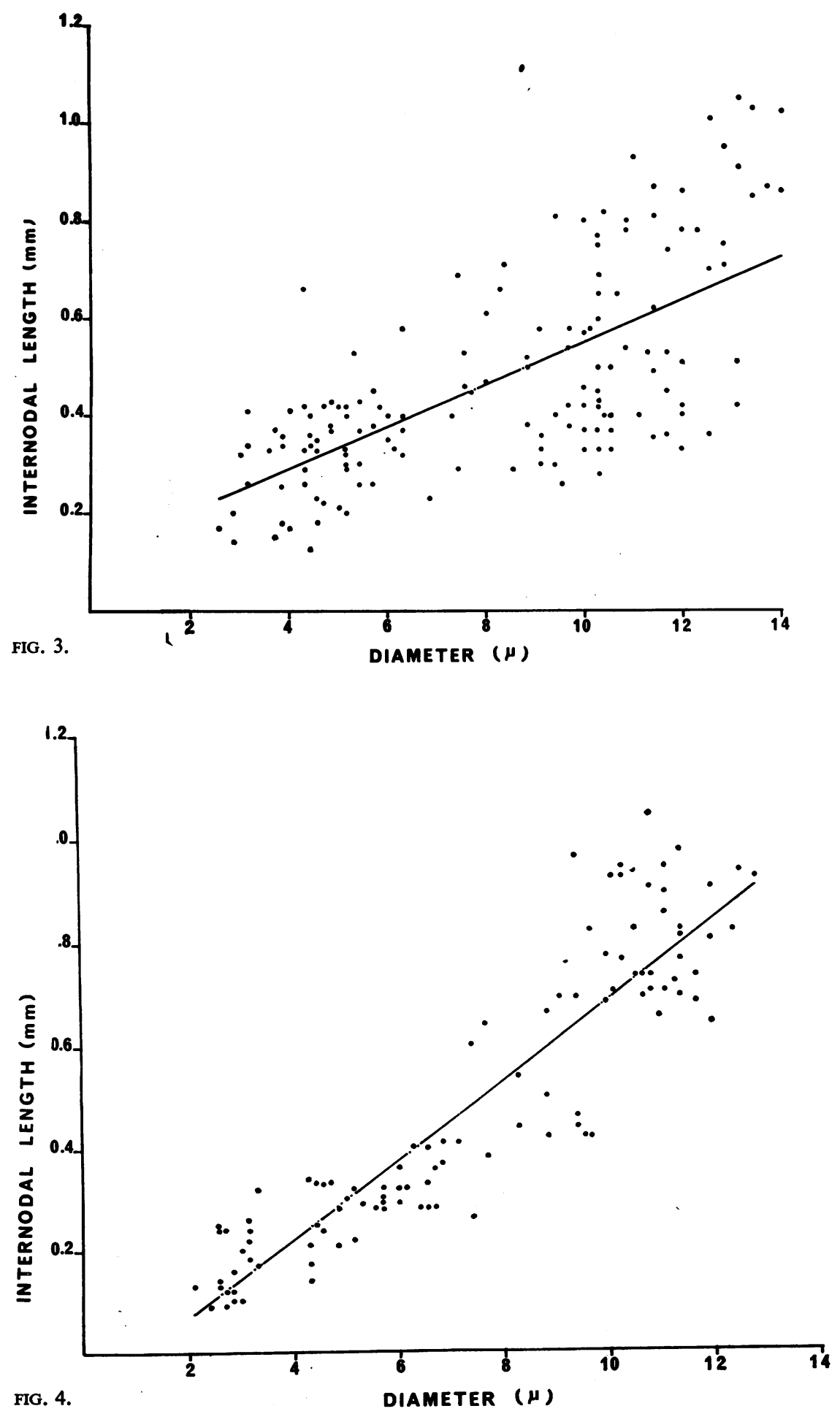


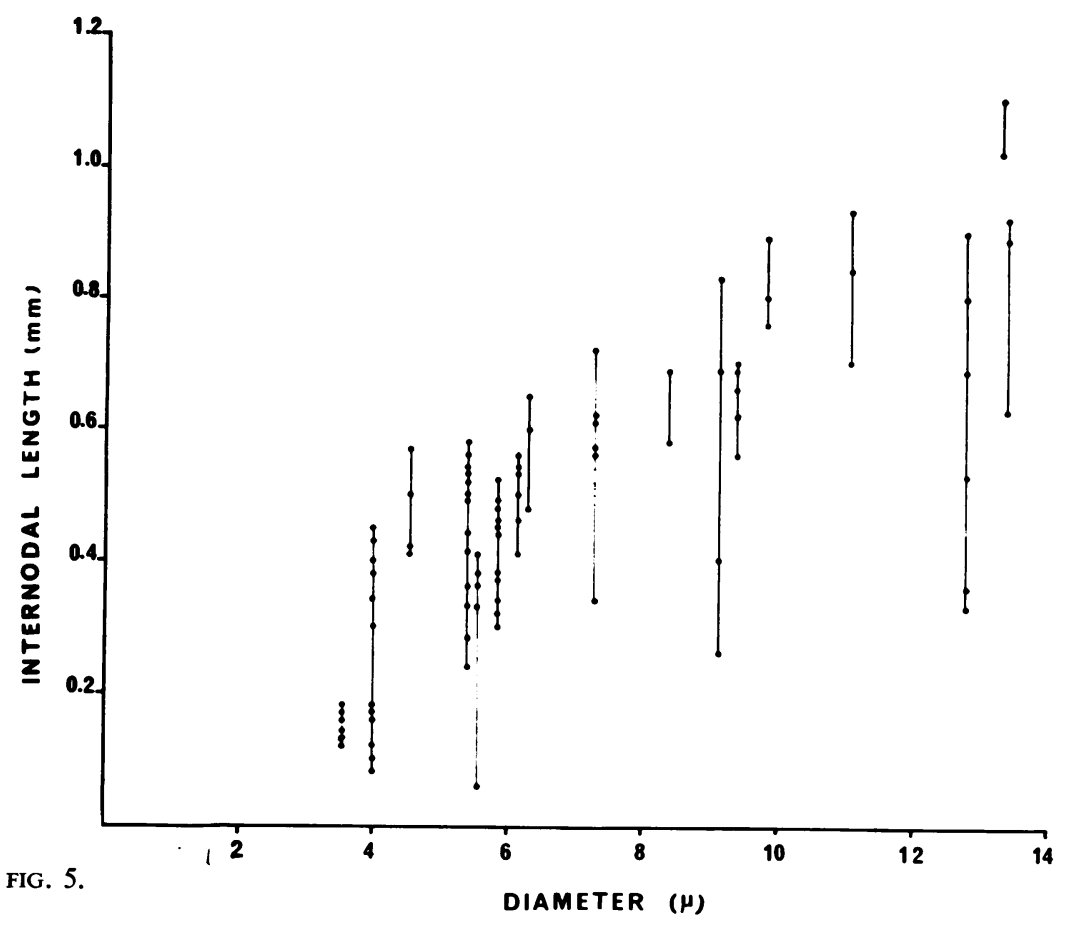

FIGS. 5, 6, and 7. Internodal lengths from individual fibres plotted against diameter of widest internodal segment and joined by vertical lines in cases 2 (Fig. 5) and 4 (Fig. 6) and control (Fig. 7).

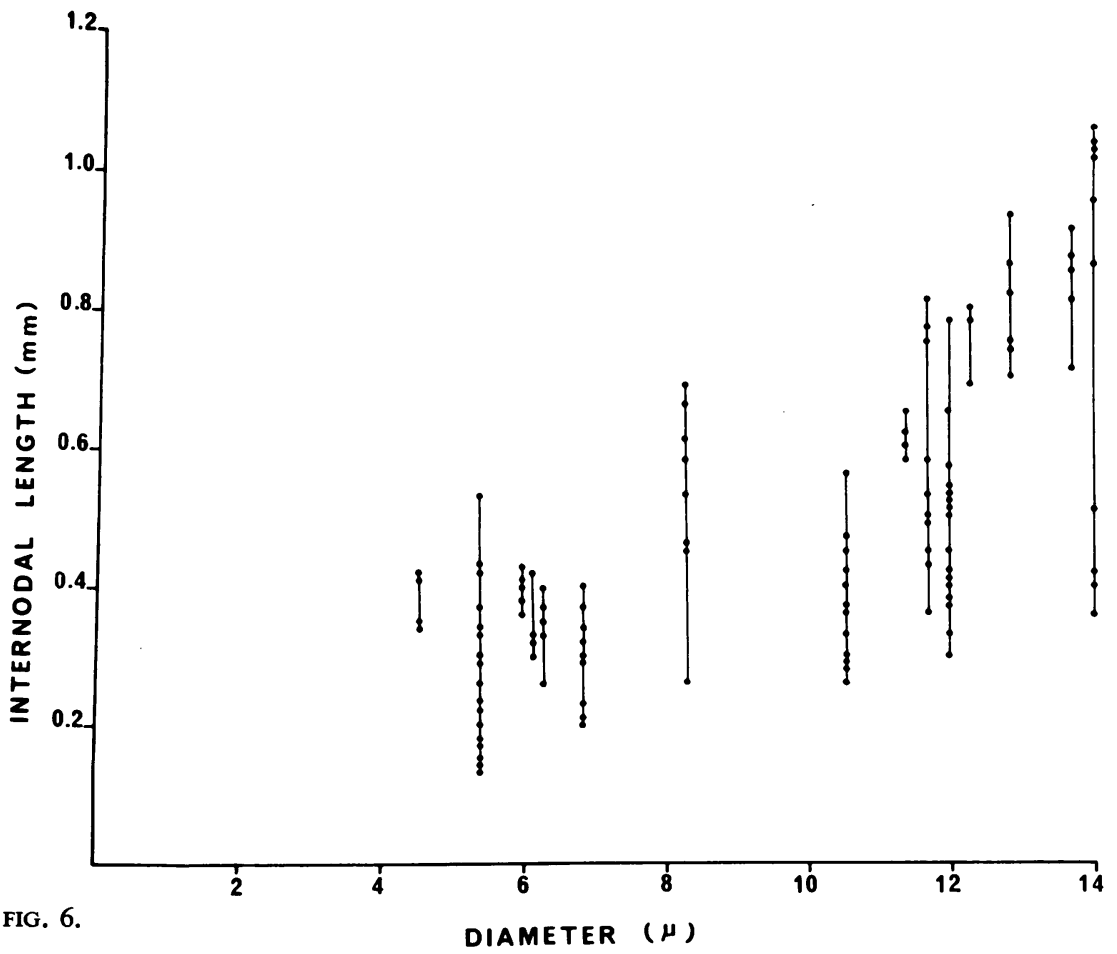




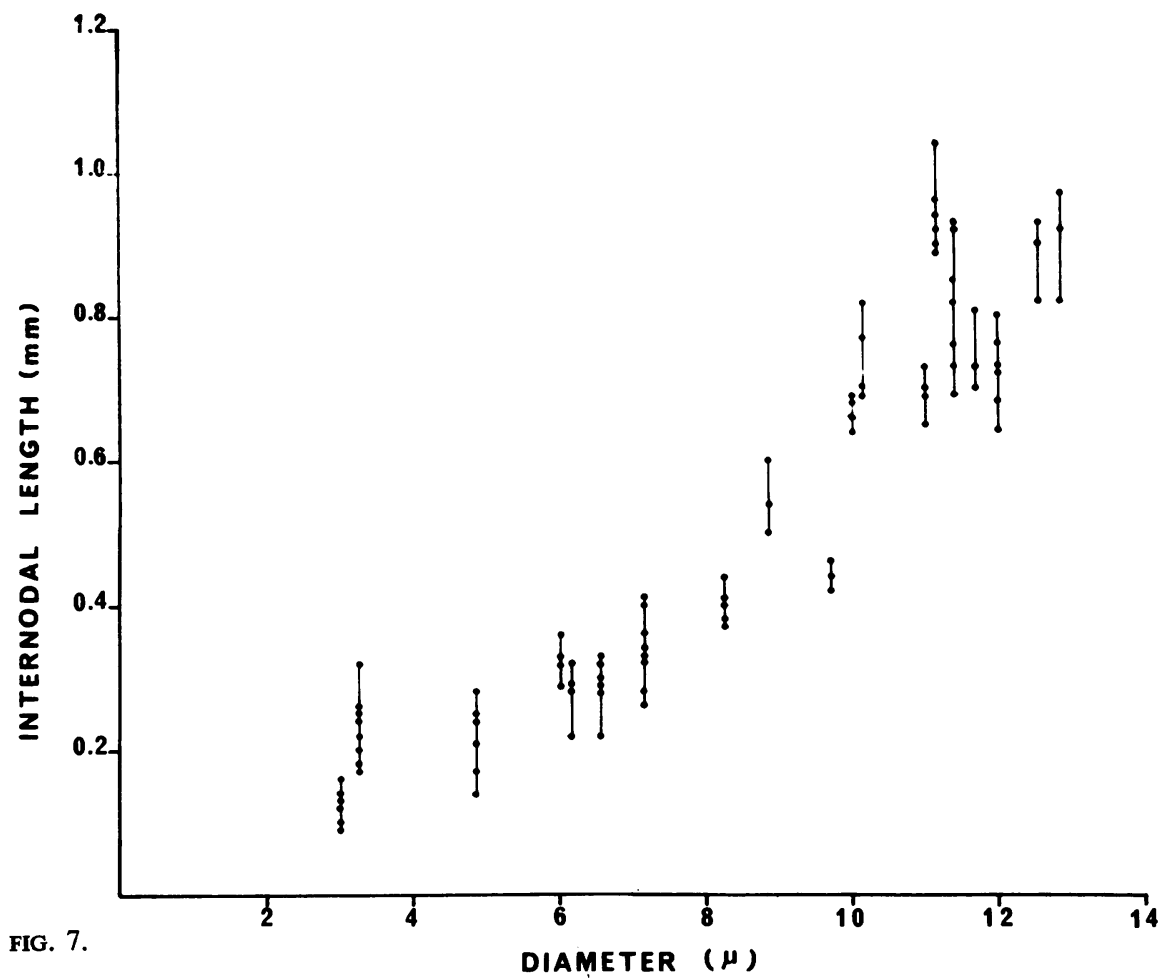

1

$110 u$

$0.02 \mathrm{~mm}$

FIG. 8a.

FIG. 8 b.

FIG. 8a. Single sural nerve fibre in case 2 (osmium tetroxide staining) showing two short less myelinated internodes between internodes of longer length. Arrows indicate nodes of Ranvier. (The figure starts at the upper left hand and thereafter represents a continuous portion of nerve fibre, the right end continuing to the left from top downwards).

FIG. 8b. A short thinly myelinated internode from the same patient. 


\section{DISCUSSION}

There have been many observations since the first report by Ranvier (1878), confirming that in the peripheral nerve trunks in vertebrates internodal distances are greater in fibres of larger diameter than in those of smaller size. The complex relationship between internodal distance and fibre diameter and the influence of growth rates are discussed by Thomas (1955) and Lascelles and Thomas (1966) and they review the relevant literature. There is general agreement that in adult man the distances between the nodes of Ranvier are longest in the larger nerve fibres and shortest in those with a smaller diameter. Also, it would appear that in the healthy adult nerve one should expect a degree of uniformity in the length of the indernodes in each nerve fibre. The sural nerves from all the patients reported here with severe chronic occlusive vascular disease involving the lower limbs showed a wider than predicted scatter when internodal length was plotted against fibre diameter. This was due to the presence of shorter internodes which were mostly found in fibres which also had internodes of normal length, suggesting the presence of segmental demyelination and remyelination in these patients. Case 1 , who was the youngest patient, had the least evidence of demyelination. He had a shorter period of symptoms attributable to ischaemia than the others and the angiogram showed the block of the artery at a lower level. There is no age influence, as the most marked changes were in two patients under the age of 50 years and in another aged 57 years. The patients in this series all showed clinically severe evidence of occlusive vascular disease in the lower limbs which had been present from months to years. None had evidence of diabetes or other such neuropathy and the distribution of neurological changes in cases 4-6 could be attributed to the severe ischaemia (Hutchinson and Liversedge, 1956). However, there is no way of assessing the actual degree of ischaemia of the nerves or how long the ischaemic process has been present though obviously it is slow and chronic and without any sudden total loss of blood to an area as occurs in cuff or tourniquet lesions, or in Volkmann's contracture.

Denny-Brown and Brenner (1944a and b) investigated the changes produced by cuff pressure, tourniquet, and spring clip in the sciatic trunk of cats. They produced evidence that the rapidity of paralysis is an expression of relative degrees of ischaemia and not a direct consequence of pressure on nerve fibres. They found that if care is taken to avoid angulation no immediate structural damage is apparent in the nerve within two hours after the application of high pressure and resulting block of conduction. One of the earliest histological changes was widening of the node of Ranvier due to loss of myelin. The axis cylinder stained feehly or not at all with silver stain where the myelin was deficient. The remaining intervening segment of the axis cylinder was thickened. Sections taken below the region of compression showed progressively shorter thinned segments and longer thickened segments of axon until normal structure was regained. Such lesions were considered by Denny-Brown and Brenner to be characteristic of ischaemia produced by pressure and giving centripetal paralysis with delayed recovery without degeneration (they term this the 'intermediate' type of pressure lesion). More severe lesions gave rise to axonal degeneration. The animal experiments were in agreernent with the careful clinical study made earlier by Lewis, Pickering, and Rothschild (1931) who found that placing a cuff round the limb at suprasystolic pressure produced paralysis, usually after a latency of 25 minutes. These workers showed that when paralysis had commenced, the placement of a second cuff below the first, with the same pressure, and then removal of the first cuff, was followed by recovery from the paralysis and its reassertion after a further similar latency. They were of the opinion that pressure produced local ischaemia and that the centripetal progress and selective character of the paralysis were explained by greater sensitivity of larger nerve fibres to anoxia. Therefore, as the effects of such pressure are mediated by the mechanism of ischaemia, it would seem that the segmental demyelination described in the nerve by Denny-Brown and Brenner could be considered due to and characteristic of some degree of ischaemia. Blunt (1960), in experiments on rabbits in which he examined single nerve fibres, showed that interference with the regional nutrient vessels of small nerve trunks, even when combined with nerve ligature, only occasionally produced ischaemic fibre degeneration in the devascularized segment. In contrast, when the devascularization was accompanied by insulating the nerve trunk from the surrounding tissues by means of polyethylene film, degenerative changes in the myelin sheath and axon occurred which differed from pure Wallerian degeneration. In contrast to Wallerian degeneration some fibres remained normal, while others showed slight degenerative changes similar to those found by Denny-Brown and Brenner. Blunt attributed his own more severe changes to ischaemia. Holmes, Highet, and Seddon (1944) studied the upper limb nerves in six patients who had suffered Volkmann's ischaemic contracture. They found no segmental demyelination. The nerve fibres showed changes varying from destruction of axons and myelin 
sheaths, as in uncomplicated Wallerian degeneration, to a great increase in the collagen in the endoneurium sometimes leading to complete collagenous replacement of the nerve bundle. One nerve was entirely necrotic.

Although the lesions produced by Denny-Brown, Blunt, and Holmes et al., can be taken to result in the main from ischaemia, the differential structural changes must be related to the initial severity of the ischaemic process and its extent. As stated by Holmes et al., it can be assumed that in the cases of Volkmann's contracture there was an initial period of acute ischaemia at the time of the injury. 'In the regions in which this ischaemia was not sufficient to cause necrosis-obliteration of the nerve fibres, the nerve lesion may have involved either destruction of the axons and myelin of the fibres or only local demyelination'. The experiments of Blunt demonstrated how the nutritional requirements of nerve fibres may be effectively met even after ligature of vasa nervorum. In man one might expect that various anastomotic arrangements within the nerve could protect the nerve fibre from the effect of severe decrease in blood supply through their nutrient arteries. In the six cases described here such a severe decrease in blood flow to the legs had been present for several months to several years, and it is suggested that the evidence of segmental demyelination in cases 1-6 is the result of ischaemia. It is noteworthy that in cases 5 and 6 (aged 64 and 67) there was also evidence of axonal degeneration and regeneration of fibres as was found by Lascelles and Thomas in their four oldest patients. This suggests that in old age there may be factors other than chronic ischaemia producing lesions in peripheral nerves or that the lesions are related to a much longer period of ischaemia.

Segmental demyelination of peripheral nerve was initially described in lead paralysis by Gombault (1880) and named by him 'nevrite segmentaire peri-axille'. It is the characteristic lesion in experimental allergic neuritis (Cragg and Thomas, 1964), diabetic neuropathy (Gilliatt, 1965; Thomas and Lascelles, 1965), and in diphtheritic neuritis (Waksman, Adams, and Mansmann, 1957). The reason for the localization of the earliest lesions to the region of nodes of Ranvier is unknown. Lubinska (1959) (quoted by Cragg and Thomas, 1964) suggested that there is a gradient of stability of the myelin sheath between the region of the Schwann cell nucleus and the ends of the internodes. The metabolic activity may be particularly high in the Schwann cell cytoplasm in the paranodal region, judging by the large numbers of mitochondria present there (Williams and Landon, 1963). One might speculate, however, that segmental demyelination is produced by the effects of blood-borne metabolites in these and by anoxia in the cases described here.

\section{SUMMARY}

The sural nerve taken by biopsy has been examined in six non-diabetic male patients aged 36-67 years with chronic occlusive vascular disease. Segmental demyelination and remyelination were present in all. It is suggested that segmental demyelination may be the initial pathological change to ischaemia which is the main factor damaging the nerve in each patient.

We are indebted to Mr. H. C. Dales, F.R.C.S., for allowing us to examine the patients who were under his care and for doing biopsies in four patients at operation. We also thank Mr. A. R. Taylor, F.R.C.S., for the biopsies in the other patients. We are grateful to Dr. P. K. Thomas and Professor R. W. Gilliatt for helpful discussion; and to Dr. J. D. Merrett for his advice on calculating the regression lines. We wish to acknowledge a generous grant from the Medical Research Council.

\section{REFERENCES}

Blunt, M. J. (1960). Ischemic degeneration of nerve fiber. Arch. Neurol. (Chic.), 2, 528-536.

Cragg, B. G., and Thomas, P. K. (1964). Changes in nerve conduction in experimental allergic neuritis. J. Neurol. Neurosurg. Psychiat., 27, 106-115.

Denny-Brown, D., and Brenner, C. (1944a). Paralysis of nerve induced by direct pressure and by tourniquet. Arch. Neurol. (Chic.), 51, 1-26.

- - (1944b). Lesions in peripheral nerve resulting from compression by spring clip. Ibid., 52, 1-19.

Fullerton, P. M., Gilliatt, R. W., Lascelles, R. G., and MorganHughes, J. A. (1965). The relation between fibre diameter and internodal length in chronic neuropathy. J. Physiol. (Lond.), 178, 26-28 $P$

Gilliatt, R. W. (1965). In Biochemical Aspects of Neurological Disorders, Second Series, edited by J. N. Cumings and M. Kremer, pp. 117-142. Blackwell, Oxford.

Gombault, A. (1880). Contribution à l'étude anatomique de la névrite parenchymateuse subaiguë et chronique.-Néyrite segmentaire péri-axile. Arch. Neurol. (Paris), 1, 11-38.

Holmes, W., Highet, W. B., and Seddon, H. J. (1944). Ischaemic nerve lesions occurring in Volkmann's contracture. Brit. $J$. Surg., 32, 259-275.

Hutchinson, E. C., and Liversedge, L. A. (1956). Neuropathy in peripheral vascular disease. Quart. J. Med., 25, 267-274.

Lascelles, R. G., and Thomas, P. K. (1966). Changes due to age in internodal length in the sural nerve in man. J. Neurol. NeuroSurg. Psychiat., 29, 40-44.

Lewis, T., Pickering, G. W., and Rothschild, P. (1931). Centripetal paralysis arising out of arrested blood flow to the limb, including notes on a form of tingling. Heart, 16, 1-32.

Ranvier, L. (1878). Leçons sur l'histologie du système nerveux. Savy, Paris.

Thomas, P. K. (1955). Growth changes in the myelin sheath of peripheral nerve fibres in fishes. Proc. roy. Soc. B., 143, 380-391.

- , and Lascelles, R. G. (1965). Schwann-cell abnormalities in diabetic neuropathy. Lancet, 1, 1355-1357.

Waksman, B. H., Adams, R. D., and Mansmann, H. C. (1957). Experimental study of diphtheric polyneuritis in the rabbit and guinea pig. J. exp. Med., 105, 591-614.

Williams, P. L., and Landon, D. N. (1963). Paranodal apparatus of peripheral myelinated nerve fibres of mammals. Nature (Lond.), 198, 670-673.

Lubińska, L. (1959). Region of transition between preserved and regenerating parts of myelinated nerve fibers. J. comp. Neurol., 113, 315-335. 